\title{
A Mixed Experimental-numerical Energy-based Approach for Fatigue Life Assessment in Notched Samples under Multiaxial Loading
}

\author{
J. Cunha, F. Nogueira, R. Branco, J.D. Costa, P. Prates, F. Berto and F.V. \\ Antunes
}

CEEMPRE, Department of Mechanical Engineering, University of Coimbra

\section{Abstract}

This paper presents a methodology to predict the fatigue lifetime in notched geometries subjected to multiaxial loading on the basis of the cumulated strain energy density. The modus operandi consists of defining an energy-based fatigue master curve that relates the cumulated strain energy density with the number of cycles to failure using standard cylindrical specimens tested under low-cycle fatigue conditions. After that, an

Corresponding Author:

Ricardo Branco

ricardo.branco@dem.uc.pt

Received: 26 November 2019

Accepted: 13 May 2020

Published: 2 June 2020

Publishing services provided by Knowledge E

(c) Cunha et al. This article is distributed under the terms of the Creative Commons

Attribution License, which permits unrestricted use and redistribution provided that the original author and source are credited.

Selection and Peer-review under the responsibility of the ICEUBI2019 Conference Committee.

\section{G OPEN ACCESS} elastic-plastic finite-element model representative of the material behaviour, notched geometry and multiaxial loading scenario is developed and used to account for the strain energy density at the crack initiation site. This energy is then averaged using the Theory of Critical Distances and inserted into the energy-based fatigue master curve to estimate the lifetime expectancy. Overall, the comparison between the experimental and predicted fatigue lives has shown a very good agreement.

Keywords: Multiaxial fatigue, Fatigue life prediction, Strain energy density

\section{Introduction}

Modern automotive industry, driven by recent environmental policies, faces an urgent need for the production of lighter vehicles with reduced fuel consumption and lower pollutant emissions [1]. Despite the constant development of new materials, high-strength steels remain key materials in this challenging scenario, mainly due to their balanced features, in particular, the low cost, excellent strength-to-weight ratio, and good corrosion resistance, among others [2].

The design of engineering components for automotive industry inevitably includes geometric discontinuities, such as holes, keyways, welded joints, section variations, etc., generically known as notches, which are responsible for stress concentration phenomena. Moreover, the loading complexity acting on such components, in many cases characterised by a multiaxial nature, combined with the stress concentration 
phenomena occurring at the critical geometric discontinuities, leads to non-trivial and challenging problems [3].

Different fatigue lifetime prediction models have been proposed to deal with notched components undergoing multiaxial loading. Among the most successful approaches, we can mention those based on the Strain Energy Density [4] and those based on the Theory of Critical Distances [5].

The underlying idea behind the SED-based approaches is that the damage caused by cyclic loading is a function of the mechanical energy input into the material. Molski and Glinka [6] proposed the Equivalent Strain Energy Density (ESED) concept, which assumes that the strain energy density of the material in the yielded zone is virtually the same as the strain energy density assuming the material to be entirely elastic. A more general formulation, based on a fatigue master curve evaluated from the sum of the positive elastic and plastic strain energy densities of representative cyclic hysteresis loops, was suggested by [7]. Lazzarin et al. [8] developed a volume-based approach, in which the SED calculations are carried out in a material-related control volume. A recent literature review on strain energy density approaches can be found in [9].

Regarding the TCD-based approaches, the key concept is the determination of a critical stress, or strain, nearby the geometric detail, considering a characteristic material length. The origin of this theory, introduced by Neuber, date back the middle of the last century [10]. The so-called Line Method (LM) states that the reference stress for fatigue life assessment can be obtained by averaging the linear-elastic stress profile over a straight line emanating from the notch root. Some years later, Peterson [11] suggested that the reference stress could be computed from the linear-elastic stress profile at a given distance from the notch root, considerably simplifying the problem. This approach is known as the Point method (PM). An overview on different applications of the TCD to fatigue problems can be found elsewhere [12].

Despite the widespread acceptance of the above-mentioned approaches, some limitations have been identified. Therefore, the development new multiaxial fatigue life assessment methods, based on the full capabilities of advanced numerical methods, and based on a limited number of experimental tests, is a great asset to the modern industry. The present paper aims at proposing a mixed experimental-numerical approach able to estimate the fatigue lifetime under multiaxial loading. The modus operandi consists of generating a fatigue master curve relating the cumulated strain energy density and the number of cycles to failure using smooth samples subjected to uniaxial straincontrolled conditions. After that, a three-dimensional elastic-plastic finite-element model is developed to account for the strain energy density at the critical locations. This energy 
in then inserted into the fatigue master curve to estimate the life expectancy of the notched components.

\section{Experimental Procedure}

The experimental fatigue campaign was conducted using a DIN 34CrNiMo6 high strength steel, oil quenched and tempered (Q\&T), supplied in the form of $20 \mathrm{~mm}$ diameter bars. Its main mechanical properties are [13]: Yield strength, $\sigma_{Y S}=967 \mathrm{MPa}$; Tensile strength, $\sigma_{U T S}=1035 \mathrm{MPa}$; Young's modulus, E = 209.8 GPa; Poisson's ratio, $v=0.296$; Cyclic hardening coefficient, $\mathrm{K}^{\prime}=1361.6 \mathrm{MPa}$; Cyclic hardening exponent, n' $=0.1041 ;$ Fatigue limit stress range, $\Delta \sigma_{0}=353 \mathrm{MPa}$; Stress intensity factor range threshold, $\Delta \mathrm{K}_{t h}=7.12 \mathrm{MPa} \cdot \mathrm{m}^{0.5}$.

In order to account for the cumulated strain energy density associated to the different stain levels, a series of low-cycle fatigue tests were performed. These tests were carried in a servo-hydraulic testing machine, under fully-reversed strain-controlled conditions $\left(R_{\varepsilon}=-1\right)$, for total strain amplitudes $(\Delta \varepsilon / 2)$ of $0.4,0.5,0.6,0.8,1.0,1.25,1.5$, and $2.0 \%$, using a constant strain rate $\left(\mathrm{d} \varepsilon / \mathrm{dt}=8 \times 10^{-3} \mathrm{~s}^{-1}\right)$. The specimens, represented in Figure 1(a), were machined according to the specifications outlined in ASTM E606 with a gage section measuring $15 \mathrm{~mm}$ in length and $8 \mathrm{~mm}$ in diameter. The stress-strain response, during the tests, was acquired from a $12.5 \mathrm{~mm}$-long strain-gage extensometer, mounted directly on the gage section, connected to a digital data acquisition system.

Multiaxial bending-torsion fatigue tests were performed in a servo-hydraulic testing machine connected to a custom-made gripping system, under in-phase constantamplitude pulsating loading conditions (i.e. $\mathrm{R}_{\sigma}=0$ ), using $16 \mathrm{~mm}$-diameter (see Figure 1(b)) and $14 \mathrm{~mm}$-diameter notched round bars. The geometric discontinuity encompassed a lateral U-shaped notch with a dimeter of $3 \mathrm{~mm}$ and a depth of $3 \mathrm{~mm}$. Three different bending moment to torsion moment ratios $(B / T)$ were considered, more specifically, $B / T=2, B / T=1$, and $B / T=2 / 3$; as well as three orientations of the bending moment with respect to the notch root $(\theta)$, that is $\theta=0^{\circ}, \theta=45^{\circ}$, and $\theta=90^{\circ}$ (see Figure 1(b)). For each loading scenario, three stress amplitudes were considered. The nominal normal stress amplitudes were in the range 179 to $298 \mathrm{MPa}$ while the nominal shear stress amplitudes varied between 45 to $245 \mathrm{MPa}$ [14]. Notch surfaces were observed in-situ using a high-resolution digital camera, and an optical device with variable magnification coupled to a micrometre driven translation stage. Images were periodically recorded through a PC-based data acquisition system. 


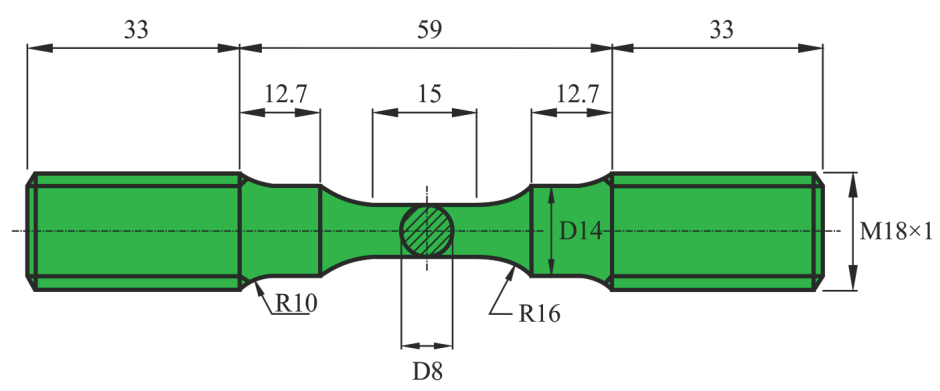

(a)
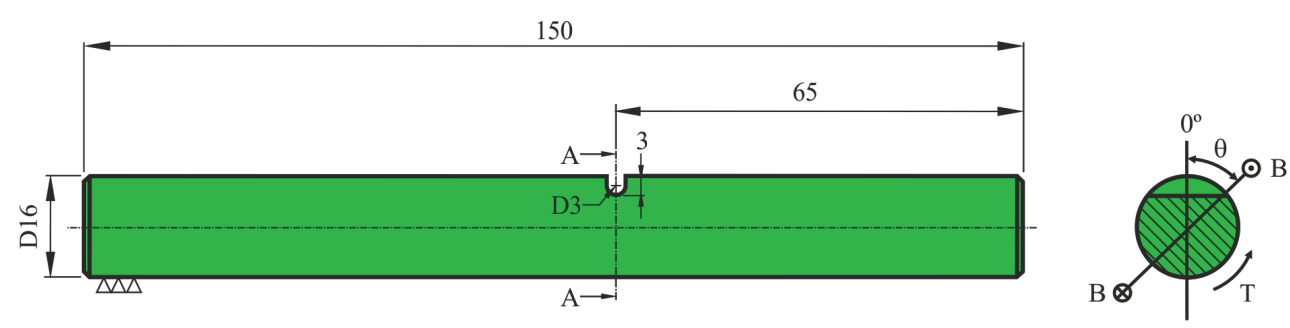

(b)

Figure 1: Specimen geometries: (a) low-cycle fatigue; (b) multiaxial fatigue.

\section{Numerical Procedure}

The cyclic response of the material was described via a purely kinematic elastic-plastic hardening model which assumes two main features: (i) the isotropic elastic behaviour is modelled by the generalised Hooke's law; and (ii) the plastic behaviour is modelled by the von Mises yield criterion, coupled with an Amstrong-Frederick non-linear kinematic hardening law under an associated flow rule. The von Mises yield surface describes the onset of plastic yielding as follows:

$$
\left(\Sigma_{22}-\Sigma_{33}\right)^{2}+\left(\Sigma_{33}-\Sigma_{11}\right)^{2}+\left(\Sigma_{11}-\Sigma_{22}\right)^{2}+3 \Sigma_{23}^{2}+3 \Sigma_{13}^{2}+3 \Sigma_{12}^{2}=2 Y_{0}^{2}
$$

where $\Sigma_{i j}$ are the components of the effective Cauchy stress tensor, $\Sigma\left(\Sigma=\sigma^{\prime}-X^{\prime}\right.$, where $\sigma^{\prime}$ is the deviatoric part of the Cauchy stress tensor, and $X^{\prime}$ is the deviatoric part of the backstress tensor), and $Y_{0}$ is the initial yield stress. The Amstrong-Frederick law describes the nonlinear kinematic hardening as follows:

$$
\dot{X}=C_{X}\left[X_{\text {sat }} \frac{\Sigma}{\bar{\sigma}}-X\right] \dot{\bar{\varepsilon}}^{p}
$$

where $\dot{X}$ is the backstress rate, $\bar{\sigma}$ is the equivalent stress, $C_{X}$ and $X_{\text {sat }}$ are material parameters, and $\dot{\bar{\varepsilon}}^{p}$ is the equivalent plastic strain rate. The isotropic and kinematic hardening parameters of the DIN 34CrNiMo6 high strength steel, determined in a previous study, are: $Y_{0}=514.47 \mathrm{MPa}, C_{x}=133.16$, and $X_{\text {sat }}=377.29 \mathrm{MPa}$ [7]. The elastic-plastic simulations of the notched parts have been conducted using the D3IMP software, an 
implicit three-dimensional finite-element code developed at the University of Coimbra by Menezes and co-workers [15]. Figure 2 shows the finite element model utilised in the numerical simulations. The mesh was created in a parametric framework with 8node hexahedral elements. At the notch region, an ultrafine pattern was generated. The remaining volume of the body was created using a coarse pattern to reduce the computational overhead. The assembled model contained 99,208 elements and 90,328 nodes. Bending moments and torsion moments were generated from a single force whose application point was defined on a case-by-case basis by adjusting the length $(h)$ and the orientation $(\theta)$ of the prismatic bar connected to the cylindrical specimen to replicate, as close as possible, the experimental tests. Five constant-amplitude load cycles, consisting of loading and unloading phases, with cyclic sinusoidal waves, were applied to achieve a stabilised cyclic behaviour. This number of cycles was defined in order to get a trade-off between computational overhead and accuracy of the stress and strain fields.

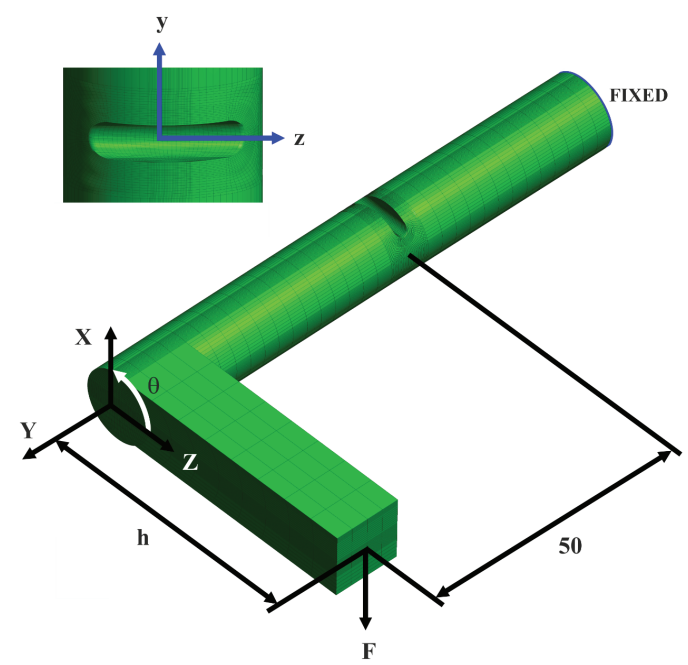

Figure 2: Example of a three-dimensional finite-element mesh $\left(B / T=1\right.$ and $\left.\theta=0^{\circ}\right)$ developed to simulate the elastic-plastic stress-strain fields at the notch region (sizes in millimetres).

\section{Results and Discussion}

Figures 3(a) and 3(b) exhibits the stress-strain response for two strain amplitudes $(\Delta \varepsilon / 2)$, respectively $\Delta \varepsilon / 2=2 \%$ and $\Delta \varepsilon / 2=0.8 \%$. A strain-softening phenomenon occurs in both cases, i.e. the uncontrolled stress decreases with the increasing number of cycles, until a stable state is achieved. In Figure 3(a), the stable behaviour is observed after 40-50 cycles (see the black hysteresis loops); in Figure 3(b), it occurs after about 500 cycles (see the black hysteresis loops). Therefore, in this steel, the stable cyclic state is reached 
generically for life ratios lower than $40 \%$ of the total number of cycles to failure. This behaviour is similar to those reported in the literature for this material $[16,17]$.

As referred to above, the first step of the proposed approach aims at developing a fatigue master curve, which relates the cumulated strain energy density $\left(\Delta W_{T, a}\right)$ with the number of cycles to failure $\left(N_{f}\right)$, developed from the a series of uniaxial straincontrolled fatigue tests conducted using smooth samples. The total strain energy per cycle $\left(\Delta W_{T}\right)$ is defined as follows:

$$
\Delta W_{T}=\Delta W_{e+}+\Delta W_{p}
$$

where $\Delta W_{e+}$ is the elastic positive strain energy density and $\Delta W_{p}$ is plastic strain energy density (see Figure 4(a)). Therefore, the cumulated strain energy density $\left(\Delta W_{T, c}\right)$ corresponds

$$
\Delta W_{T, c}=\int_{1}^{N_{f}} \Delta W_{T} d N
$$

to the total strain energy density absorbed in the entire lifetime, i.e. where $N_{f}$ represents the number of cycles to failure. Figure 4(a) plots the cumulated strain energy density against the total strain energy density per cycle for the different uniaxial strain-controlled fatigue tests performed in this research. As far as it can be seen, in a log-log scale, there is a very good correlation between both variables, i.e. a linear decreasing function between $\Delta W_{T, c}$ and $\Delta W_{T}$. Similarly, as exhibited in Figure $4(\mathrm{~b})$, there is also a very good correlation between the cumulated strain energy density and the number of cycles to failure. Both variables, in a log- log scale, can be related through a linear increasing function. Although the cumulated plastic strain energy density, also known as fatigue toughness, rarely has been addressed in the open literature, the few studies have reported power relationships between $\Delta W_{T, W}$ and $N_{f}$ which agrees with the conclusions found for the DIN 34CrNiMo6 high-strength steel [18, 19].

After the development of the fatigue master curve, represented in Figure 4(b), the procedure consists of calculating the total strain energy density at the crack initiation sites for the different multiaxial loading scenarios. In notched components, under multiaxial loading, the determination a priori of the crack initiation sites is not a trivial problem. The typical locations of the crack initiation sites for different multiaxial loading scenarios are presented in Figure 5 by the white circles. These locations are affected either by the $\mathrm{B} / \mathrm{T}$ ratio or by the $\theta$ angle. The effect of the $\mathrm{B} / \mathrm{T}$ ratio can be summarised by comparing Figures 5(a), 5(b) and 5(e). For lower levels of shear stress, i.e. higher B/T ratios, the crack nucleates near the centre of the notch (see Figure $5 \mathrm{a}$ ); nevertheless, as the B/T ratio decreases, initiation tends to occur closer to the edge of the notch (see Figures 5(b) and 5(e)). Regarding the $\theta$ angle, the results of Figures 5(b), 5(c) and 5(d) show that crack initiation locations tend to be closer to edge of the notch for higher angles. 


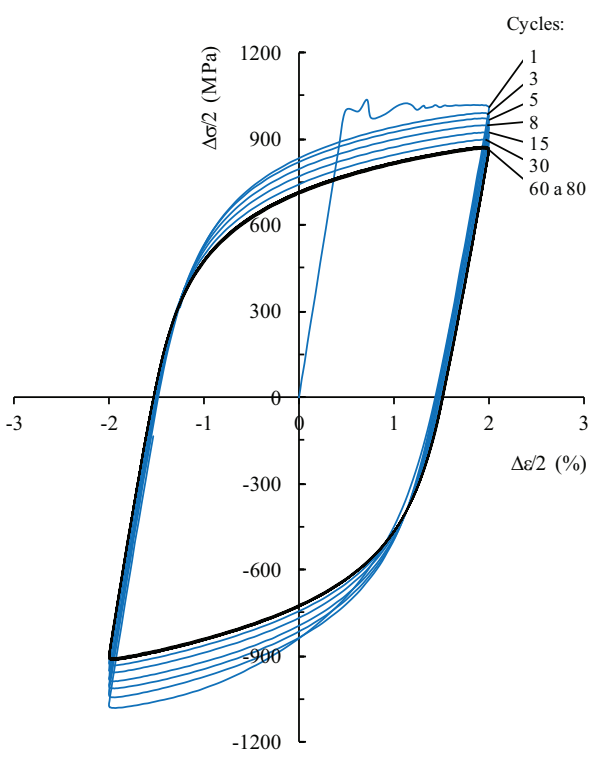

(a)

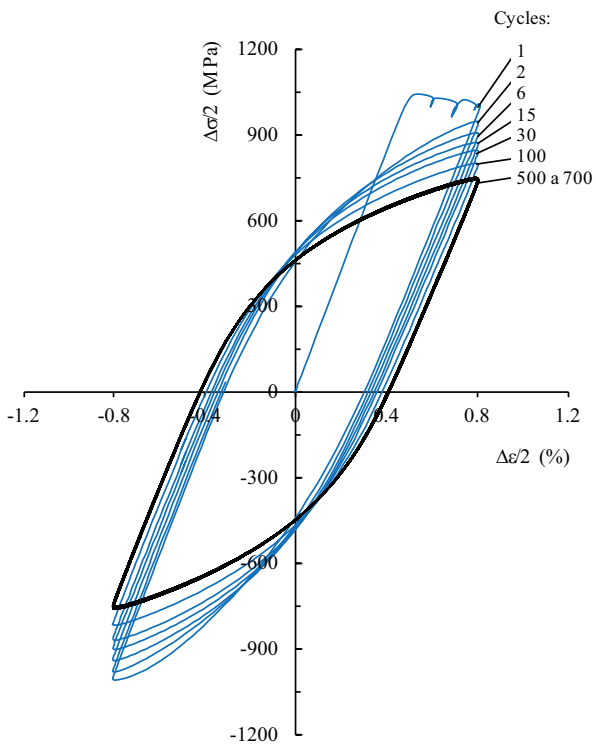

(b)

Figure 3: Stress-strain hysteresis loops of the DIN $34 \mathrm{CrNiMo6}$ high-strength steel: a) $\Delta \varepsilon / 2=2.0 \%$; b) $\Delta \varepsilon / 2=0.8 \%$.

However, the influence of this parameter is more tenuous than the $B / T$ ratio. A dominant role of the $B / T$ ratio on the surface crack paths in notched round bars has been also reported in the reference [20].

The prediction of the initiation sites is a relevant matter in fatigue design with great industrial interest since it allows the selection of adequate inspection methods. In this work, the initiation sites were predicted numerically from the elastic-plastic finite-element models assuming that initiation sites correspond to the locations at the notch surface with maximum values of the first principal stress. These locations are represented by the white squares in Figure 5 . In fact, the closeness of both the experimental and the numerical results for the various loading cases is indisputable.

Figure 5 also exhibits the macroscopic aspect of the crack paths observed in the experiments for various loading scenarios. The crack paths, as expected, are strongly affected by both the $\mathrm{B} / \mathrm{T}$ ratio and the $\theta$ angle. The former effect can be inferred from Figures 5(a), 5(b) and 5(e). It can be concluded that the higher is the $B / T$ ratio, the straighter is the crack path. This behaviour can be explained by the fact that the reduction of the $B / T$ ratio raises the level of shear stress which is associated with a higher degree of mixed-mode loading. With regard to the orientation of the bending moment with respect to the notch root, the analysis of Figures 5(b), 5(c) and 5(d) shows that as the $\theta$ angle climbs, the crack path is increasingly curved. These results can be attributed to the normal stress profile acting at the notch root which is $\theta$-dependent. Cracks paths were successfully predicted via the elastic-plastic finite-element models 

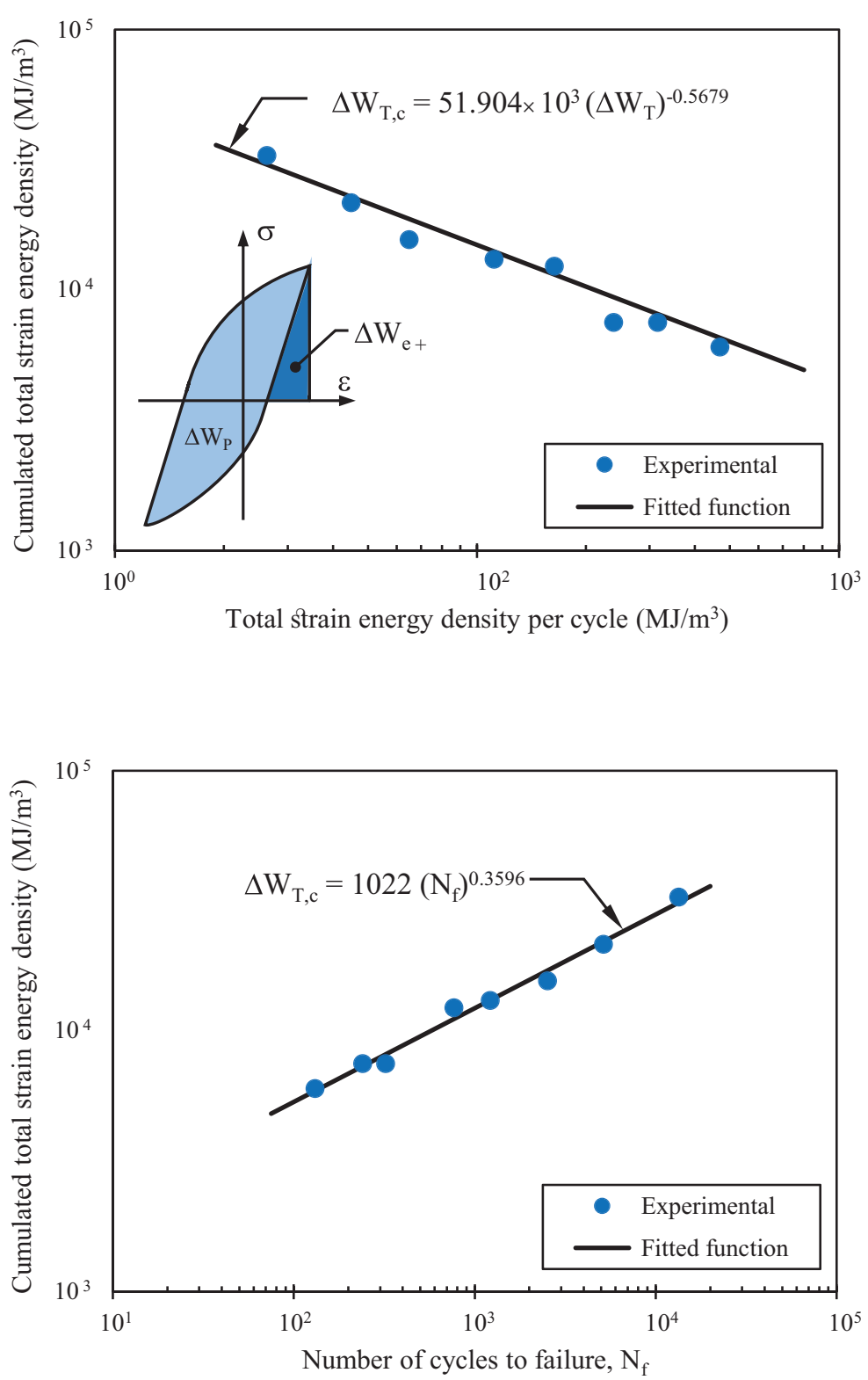

Figure 4: Relationship between: (a) the cumulated strain energy density and the total strain energy density per cycle; and (b) cumulated strain energy density and the number of cycles to failure.

on the basis of the first principal stress field. Numerical predictions are represented by the dashed white lines in Figure 5. In fact, the comparison of both the experimental and the numerical crack paths shows a very good agreement.

The total strain energy density at crack the initiation sites was computed through the three-dimensional elastic-plastic numerical models using the formulation proposed by Ellyin [21]:

$$
\Delta W_{T}=\Delta W_{e+}+\zeta \Delta W_{p}
$$




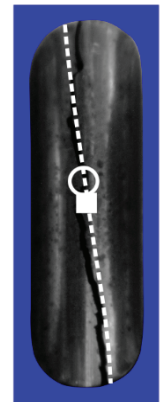

Initiation sites:

(a)

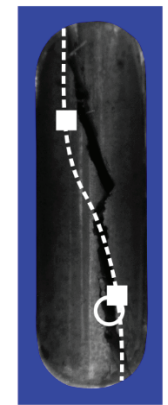

Experimental

(b)

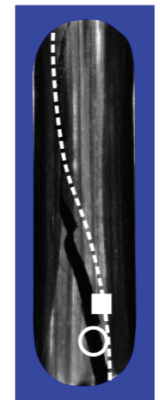

Numerical

(c)

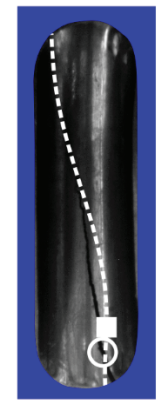

Surface crack paths:

(d)

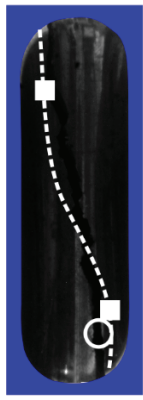

Numerical

(e)

Figure 5: Macroscopic aspect of the surface crack paths and initiation sites: (a) $B / T=2\left(0^{\circ}\right) ;(b) B / T=1\left(0^{\circ}\right)$; (c) $B / T=1\left(45^{\circ}\right)$; (d) $B / T=1\left(90^{\circ}\right)$; (e) $B / T=2 T / 3\left(0^{\circ}\right)$.

where $\zeta$ is a multiaxial coefficient. For a Masing-type material, $\Delta W_{e+}$ and $\Delta W_{p}$ are defined, respectively, by the following formulae [21]:

$$
\begin{gathered}
\Delta W_{e+}=\left\{\frac{1+v}{3 E}\left(\sigma_{e q}^{\max }\right)^{2}+\frac{1-2 v}{6 E}\left[\sum_{i=1}^{3}\left(\sigma_{i}^{a}+\sigma_{i}^{m}\right)\right]\right\} \\
\Delta W_{p}=\left\{\frac{2\left(1-n^{\prime}\right)+v}{1+n^{\prime}}\left(2 K^{\prime}\right)^{-1 / n^{\prime}}\left(\Delta \sigma_{e q}\right)^{\left(1+n^{\prime}\right) / n^{\prime}}\right\}
\end{gathered}
$$

where $v$ is the Poisson's ratio, $\mathrm{E}$ is the Young's modulus, $\sigma_{e q, \max }$ is the maximum von Mises equivalent stress, $\Delta \sigma_{e q}$ is the von Mises equivalent stress range, $\sigma_{i, a}$ are the alternating components of the principal stresses, $\sigma_{i, m}$ are the mean components of the principal stresses, $K^{\prime}$ is the cyclic hardening coefficient, and $n^{\prime}$ is the cyclic hardening exponent. Figure 6 plots, as an example, the variation of the total strain energy density with the distance from the crack initiation site $\left(\mathrm{B} / \mathrm{T}=2\right.$ and $\left.\theta=90^{\circ}\right)$. Irrespective of the $\mathrm{B} / \mathrm{T}$ ratio and the $\theta$ angle, $\Delta W_{T}$ is maximum at the notch surface and then gradually decreases to an asymptotical value. As is well-known, the use of the energy at the surface results in too conservative values. Therefore, in order to estimate the number of cycles to failure for the multiaxial loading scenarios, we have calculated an effective value of $\Delta W_{T}\left(\Delta W_{T, \text { eff }}\right)$ by applying the Line Method of the Theory of Critical Distances (see Figure 6). The critical distance $\left(a_{0}\right)$ of the DIN 34CrNiMo 6 high-strength steel for $R_{\sigma}=0$ is equal to equal to $129 \mu \mathrm{m}[13]$.

This effective value of $\Delta W_{T}$, which corresponds to the total strain energy density absorbed per cycle for the notched geometries under multiaxial loading, is then inserted into the function that relates $\Delta W_{T, c}$ and $\Delta W_{T}$ of Figure 4(a) to estimate the corresponding cumulated strain energy density. Finally, the predicted fatigue life $\left(N_{p}\right)$ is accounted for via the $\Delta W_{T, c}-N_{f}$ relationship of Figure 4(b) using the cumulated strain energy density determined in the previous step. Figure 7 compares the predicted and the 


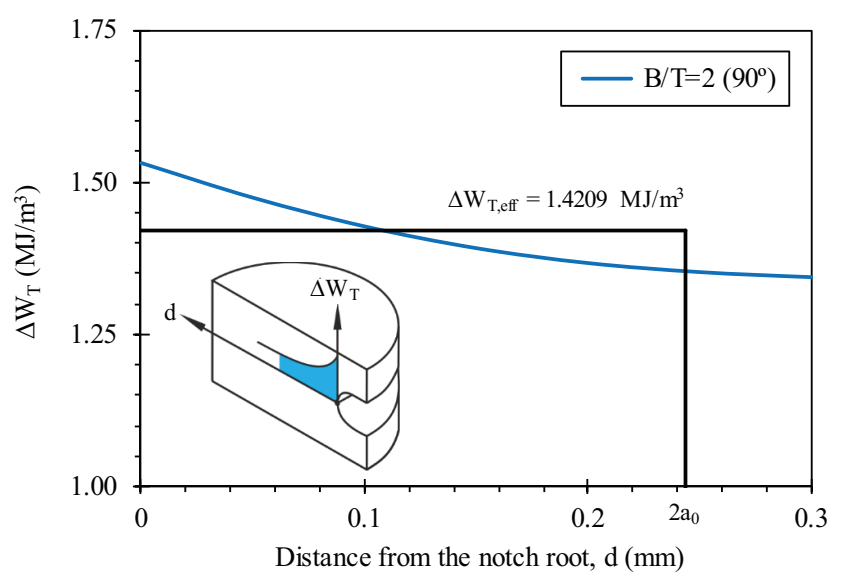

Figure 6: Evolution of total strain energy density over a straight-line emanating from the initiation site in a direction normal to the notch surface for $\mathrm{B} / \mathrm{T}=2$ and $\theta=90^{\circ}$.

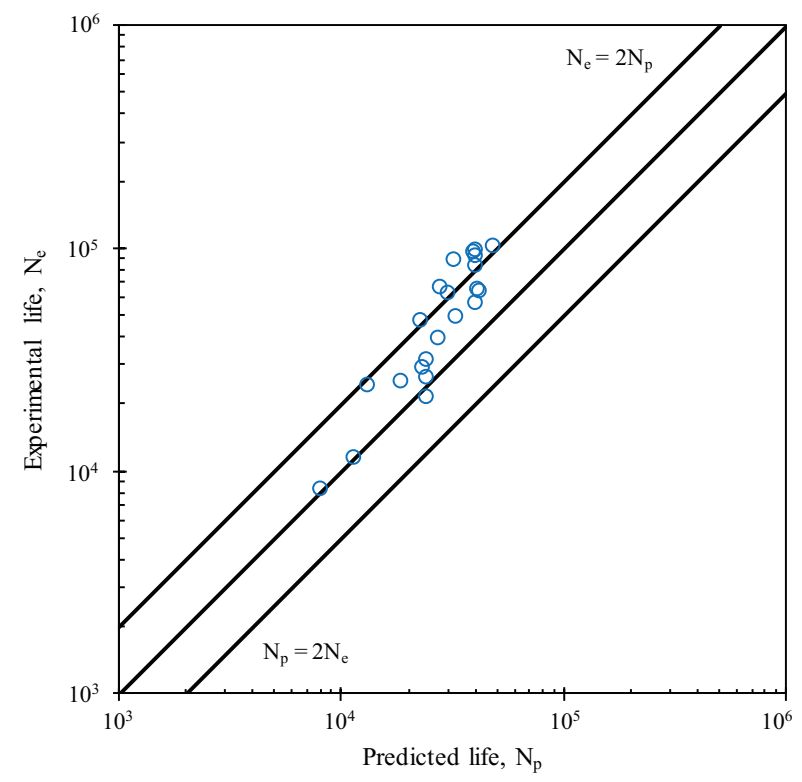

Figure 7: Comparison between the predicted fatigue life $\left(\mathrm{N}_{p}\right)$ and the experimental fatigue life $\left(\mathrm{N}_{e}\right)$ for the differentmultiaxial loading scenarios.

experimental fatigue lives for the different loading scenarios studied here. For the sake of the clarity, two scatter bands with factors of two were drawn, i.e. $N_{p}=2 N_{i}$ and $N_{i}=2 N_{p}$. As can be seen, both the experimental results and the numerical predictions are very well correlated. Moreover, the points outside the delimited region are in the conservative side which is another positive aspect. 


\section{Conclusions}

In this paper, fatigue crack initiation lifetime for circular cross-sections bars made of 34CrNiMo6 high-strength steel with U-shaped lateral notches subjected to in-phase bending-torsion loading was studied. Fatigue crack initiation lifetime was predicted using an approach based on the cumulated strain energy density. The following conclusions can be drawn:

- The relationship between the total strain energy density per cycle and the cumulated strain energy density absorbed in the entire lifetime, in a log-log scale, can be established for this material via a linear decreasing function. Similarly, in a log-log scale, the relationship between the cumulated strain energy density and the lifetime can be established through a linear increasing function;

- Crack initiation sites, crack initiation angles, and surface crack paths at the notch surface have been successfully predicted in both notch configurations from linearelastic finite-element models via the maximum value of the first principal stress at the notch surface, first principal direction at the initiation site, and first principal stress field at the notch surface, respectively;

- The mixed experimental-numerical procedure proposed in this research allows the estimation of the fatigue lifetime for notched samples subjected to in-phase bending-torsion loading. In the entire range studied, a very good correlation between the experimental and the predicted lives was found.

\section{References}

[1] Mayyas, A.; Qattawi, A.; Omar, M.; Shana, D.: "Design for sustainability in automotive industry: a comprehensive review". Renew. Sust. Energ. Rev., Vol.16 (2012) pp. 184562.

[2] Schmitt, J.H.; lung, T.: "New developments of advanced high-strength steels for automotive applications”. C. R. Physique Vol. 19 (2018) pp. 641-656.

[3] Carpinteri, A.; Spagnoli, A.; Vantadori, S.; Viappiani, D.: "A multiaxial criterion for notch high-cycle fatigue using a critical-point method". Eng. Fract. Mech. Vol. 75 (2008) pp. 1864-1874.

[4] Zhu, S.P.; Liu, Y.; Liu, Q.; Yua, Z.Y.: "Strain energy gradient-based LCF life prediction of turbine discs using critical distance concept”. Int. J. Fat. Vol. 113 (2018) pp. 33-42.

[5] Taylor, D.; "Geometrical effects in fatigue: a unifying theoretical model". Int. J. Fatigue Vol. 21 (1999) pp. 413-420.

[6] Molski, K; Glinka, G.: "A method of elastic-plastic stress and strain calculation at a notch root". Mater. Sci. Eng. Vol. 50 (1981) pp. 93-100. 
[7] Golos, K.; Ellyin, F.: "Generalization of cumulative damage criterion to multilevel cyclic loading". Theoret. Appl. Fract. Mech. Vol. 7 (1987) pp. 169-176.

[8] Lazzarin, P.; Zambardi, R.: "A finite-volume-energy based approach to predict the static and fatigue behaviour of components with sharp V-shaped notches". Int. J. Fract. Vol. 112 (2001) pp. 275-298.

[9] Berto, F.; Lazzarin, P.: "A review of the volume-based strain energy density approach applied to V-notches and welded structures". Theoret. Appl. Fract. Mech. Vol. 52 (2009) pp. 183-194.

[10] Neuber, H.: "Theory of notch stresses: principles for exact calculation of strength with reference to structural form and material". Springer, Berlin, Germany, 1958.

[11] Peterson, R.E.: "Notch sensitivity". in: G. Sines, J.L. Waisman (Eds.), Metal Fatigue, McGraw Hill, New York, 1958, pp. 293-306.

[12] Susmel, L.: "The theory of critical distances: a review of its applications in fatigue". Eng. Fract. Mech. Vol. 75 (2008) pp. 1706-1724.

[13] Branco, R.; Costa, J.D.; Berto, F.; Antunes, F.V.: "Fatigue life assessment of notched round bars under multiaxial loading based on the total strain energy density approach”. Theo. Appl. Fract. Mech. Vol. 97 (2018) pp. 340-348.

[14] Branco, R.; Prates, P.A.; Costa, J.D.; Borrego, L.P.; Antunes, F.V.: "Rapid assessment of multiaxial fatigue lifetime in notched components using an averaged strain energy density approach". Int. J. Fat. Vol. 124 (2019) pp. 89-98.

[15] Menezes, L.F.; Teodosiu, C.: "Three-dimensional numerical simulation of the deep drawing process using solid finite elements”. J. Mater. Proc. Technol. Vol. 97 (2000) pp. 100-106.

[16] Dutta, K.; Divya Bharathi, K.: "Effect of prior ratcheting deformation on low cycle fatigue behaviour of AISI 4340 steel". Lecture Notes in Mechanical Engineering. Fracture, Fatigue and Wear (2019) pp. 759-767, Springer, Singapore.

[17] Branco, R.; Costa, J.D.; Antunes, F.V.: "Low-cycle fatigue behaviour of 34CrNiMo6 high strength steel". Theo. Appl. Fract. Mech. Vol. 58 (2012) pp. 28-34.

[18] Li, D.; Nam, W.; Lee, C.: "A strain energy-based approach to the low-cycle fatigue damage mechanism in a high-strength spring steel". Metall. Mater. Trans. A Vol. 29 (1998) pp. 1431-1439.

[19] Callaghan, M.; Humphries, S.; Law, M.; Ho, M.; Bendeich, P.; Li, H.; Yeung W.: Energybased approach for the evaluation of low cycle fatigue behaviour of $2.25 \mathrm{Cr}-1 \mathrm{Mo}$ steel at elevated temperature. Mater. Sci. Eng. A Vol. 527 (2010) pp. 5619-5623.

[20] Branco, R.; Costa, J.D.; Antunes, F.V.: "Fatigue behaviour and life prediction of lateral notched round bars under bending-torsion loading". Eng. Fract. Mech. Vol. 119 (2014) pp. 66-84.

[21] F. Ellyin. Fatigue damage, crack growth and life prediction. Chapman Hall, London, UK, 1997. 